
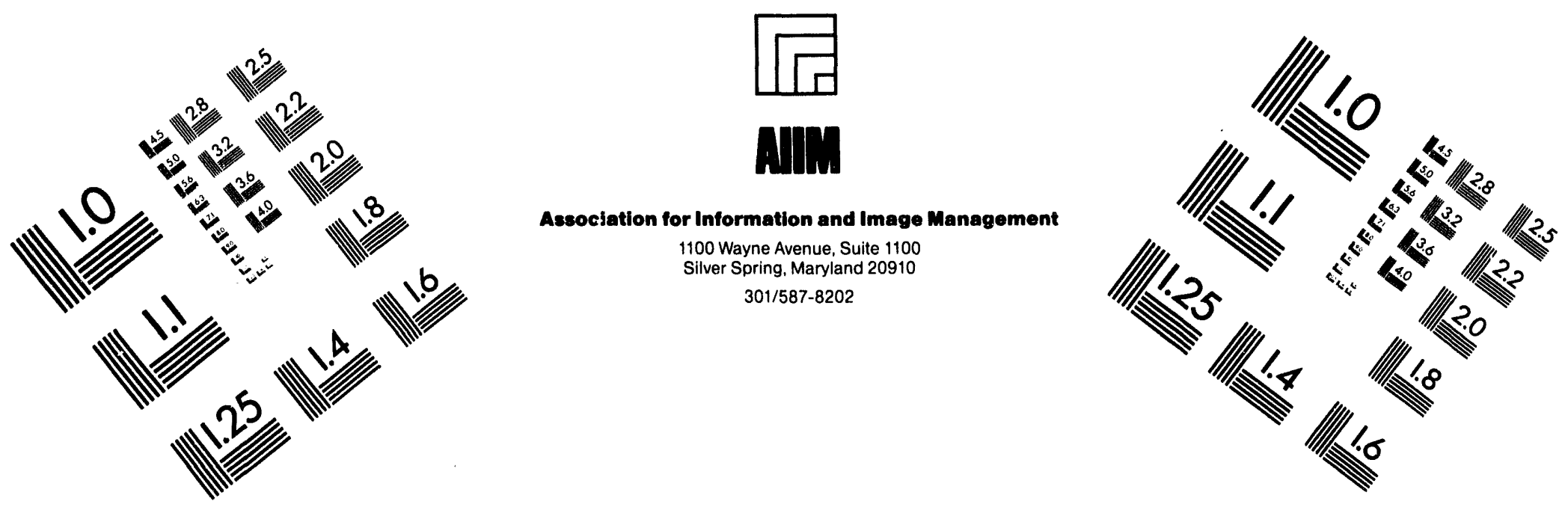

\title{
Centimeter
}

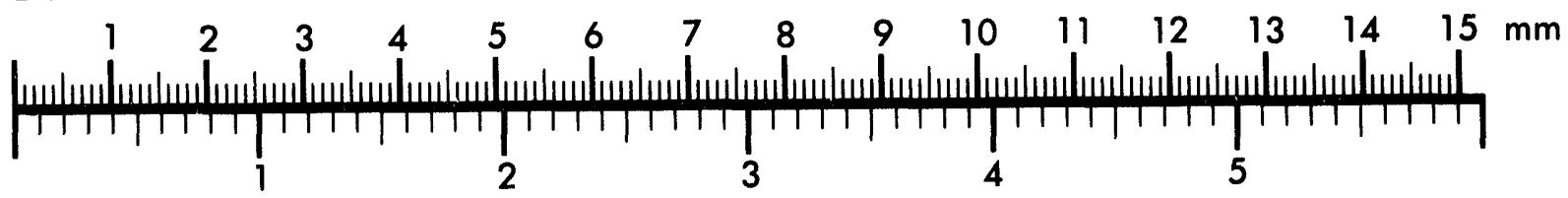
Inches
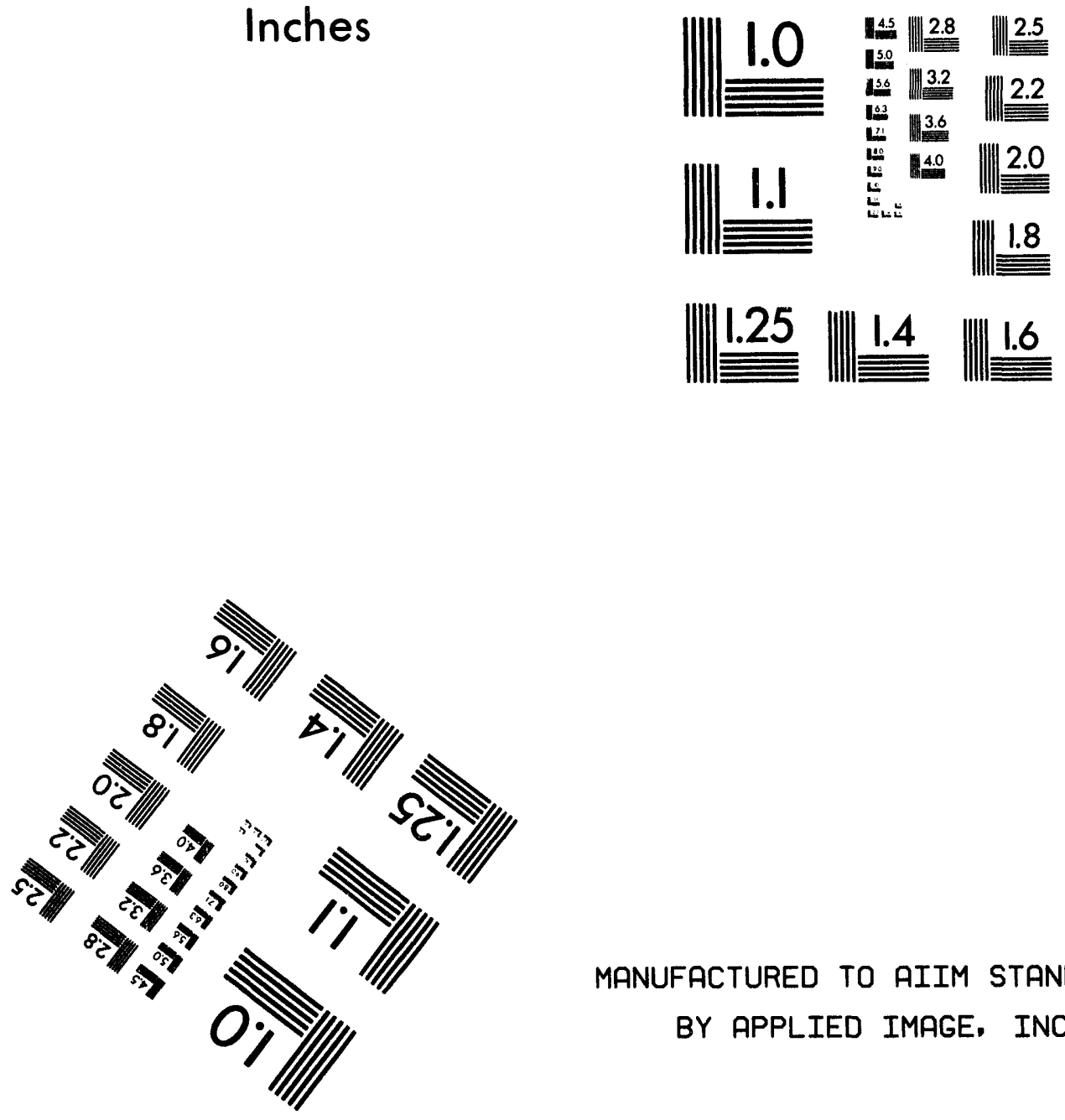

MANUFACTURED TO AIIM STANDARDS

BY APPLIED IMAGE. INC.

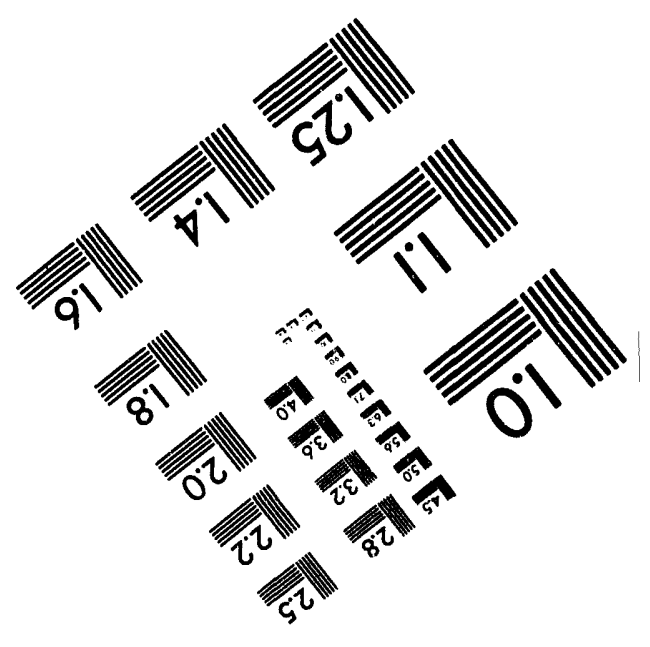



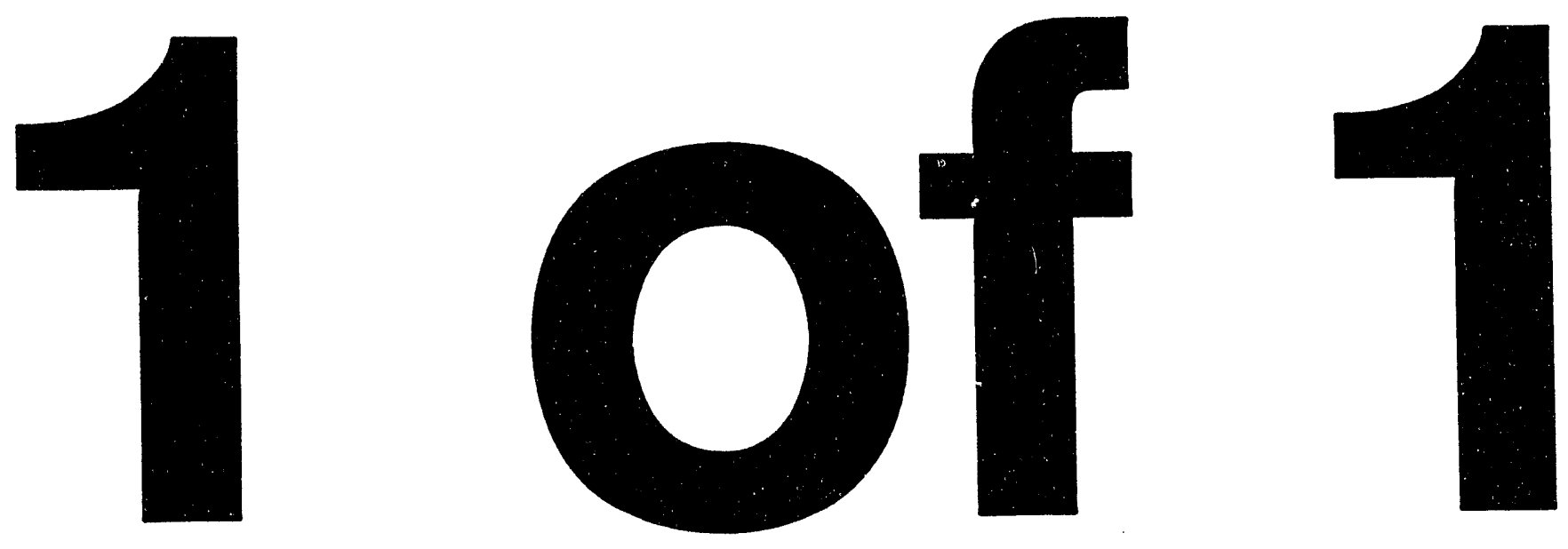


\section{$\cos 8-940723--7$}

UCRL-JC- 117604

PREPRINT

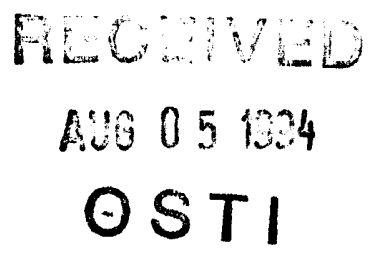

RATE CONTROLLED SYNTHESIS OF COMPOSITION MODULATED, METAL-OXIDE THIN FILMS

A. F. Jankowski

This paper was prepared for submittal to SPIE's Annual Meeting International Symposium on

Optics, Imaging, and Instrumentation

in San Diego, CA on July 24-29, 1994.

July 1994

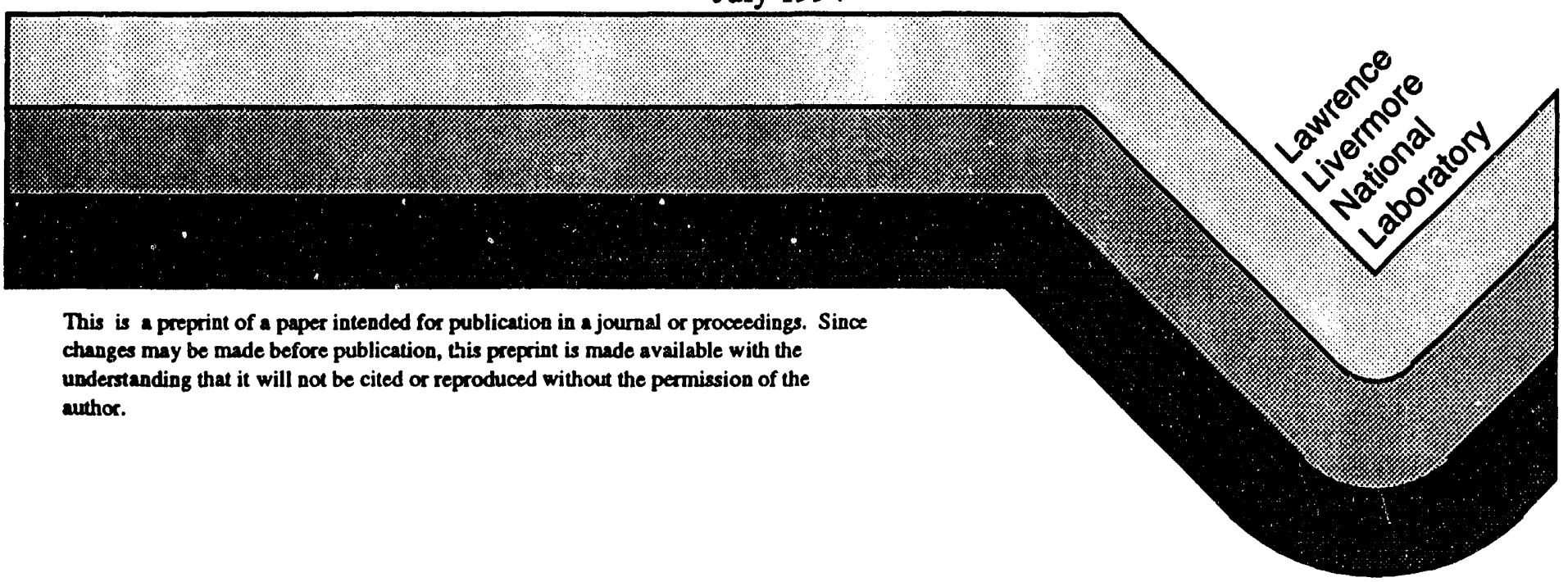

MASTER

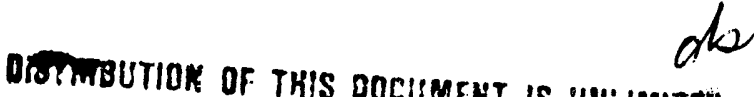




\section{DISCLAIMER}

This document was prepared as an account of work spoinsored by an agency of the United States Government. Neither the United States Government nor the University of California nor any of their employees, makes any warranty, express or implied, or assumes any legal liability or responsibility for the accu racy, completeness, or usefulness of any information, apparatus, product, or process disclosed, or represents that its use would not infringe privately owned rights. Reference herein to any specific commercial products, process, or service by trade name, trademark, manufacturer, or otherwise, does not necessarily constitute or imply its endorsement, recommendation, or favoring by the United States Government or the University of California. The views and opinions of authors expressed herein do not necessarily state or reflect those of the United States Government or the University of Califormia, and shall not be used for advertising or product endorsement purposes. 
Rate controlled synthesis of composition modulated, metal-oxide thin films

\author{
Alan F. Jankowski \\ Lawrence Livermore National Laboratory, Chemistry and Materials Science \\ University of California, P.O. Box 808, Livermore, CA 94551-9900
}

\begin{abstract}
The development of advanced deposition technologies is continuously evolving for the synthesis of oxide coatings used in optical applications. Recent progress is made in the use of magnetron sputtering to reactively deposit metal-oxide thin films. The sputter deposition parameters are chosen with respect to the reaction kinetics of the metal-oxide system to enable a variation of composition along the film growth direction. The key process parameter to control is the sputtering rate of the target. The shape of the composition profile directly corresponds to the preselected variation of deposition rate. By simply varying the sputtering rate using a working gas that consists of an inert-oxygen mixture, structures are synthesized with composition profiles which can be either abrupt or graded in the growth direction. The result is a compositionally modulated structure of the metal-oxide system. This procedure for composition modulated synthesis is demonstrated for metals which are highly reactive with oxygen as well as for those metals which are not. The development of this deposition methodology will facilitate the design of metal oxide films for optical applications, as in gradient-index filters for example. Results are presented for the reactive sputter deposition of metal oxide coatings in the yttrium-oxide, molybdenum-oxide, and copperoxide systems.
\end{abstract}

Keywords: metal-oxide, reactive sputtering, composition modulated, thin films

\title{
1. INTRODUCTION
}

The conventional method of synthesizing metal-oxide thin films utilizes flow and pressure regulation of the reactive gas to control the composition of the growing film. As an example, consider the reactive sputter deposition of a yttrium target with a working gas of Ar-20\%Oxygen. [I] At a constant target power density $\left(9.5\right.$ Watts $\left.\mathrm{cm}^{-2}\right)$ and constant working gas pressure $(0.40 \mathrm{~Pa})$, a hysteresis is formed between the change in gas flow and the resulting deposition rate (Fig. 1). In this scenario, at low flow rates the target sputters in metallic mode whereas when the flow is raised to a sufficiently high rate the deposition rate drops dramatically as the target surface is poisoned by the reactive gas and therefore sputters as an oxide. To remove the surface oxide from the sputtering target, the gas flow rate must then be reduced until there is insufficient reactive gas present to equilibrate the oxide layer at the target surface. A finite interval of time, however short, is required to change the sputtering mode of the target in a reactive gas using the method of cycling the working gas flow (and/or pressure). This time interval is equivalent to the time required for the pressure and flow controls to stabilize the change in gas flow and pressure plus the time required for the surface reaction between the target metal and reactive gas to reach an equilibrium state.

An alternative procedure has been recently developed to synthesize metal-oxide films. In this procedure, the time required to change sputter modes (metallic $<->$ oxide) is greatly reduced. The effect of sputter rate variation coupled to the reaction kinetics of the metal and oxygen enables the synthesis of both metastable and equilibrium oxide phases. First, the working gas composition, pressure and flow conditions are predetermined to enable the target sputtering mode as metallic. Then, rather than utilize a cycling of the working gas pressure and/or flow, the target power density can be cycled to produce an instantaneous change in the deposition rate. The change in deposition rate at the film surface produces an accompanying change in the metal-to-oxygen composition in the growing film. This method takes advantage of forming the desired metalto-oxygen composition in the deposition flux or at the film surface rather than at the target surface. A broader range of metalto-oxygen composition is attainable using this method. In fact, a continuous variation of oxide composition is possible for those metal-oxide systems which contains only a few equilibrium phases. For example, a continuous variation of metallic composition (from 40 to 75 at.\% Y) is demonstrated for the yttrium-oxide system whereas the only equilibrium phase is $\mathrm{Y}_{2} \mathrm{O}_{3} \cdot{ }^{[1]}$ Another example is found in the synthesis of metal-rich oxide phases well beyond the 25-33 at.\% Mo composition found in conventional bulk processing. $[2,3]$ For the Mo-O system (Fig. 2), the deposition rate can be continuously varied with applied target power where a constant Ar-20\% Oxygen working gas pressure (of $0.67 \mathrm{~Pa}$ ) and flow (of $21.5 \mathrm{cc} \mathrm{min}-1$ ) are used to sputter a $6.35 \mathrm{~cm}$ diameter molybdenum target. As a consequence, this method produces a rate dependent behavior in the film composition (as measured using Auger clectron spectroscopy coupled with depth profiling) parallel to the target power. $[2,3]$ 


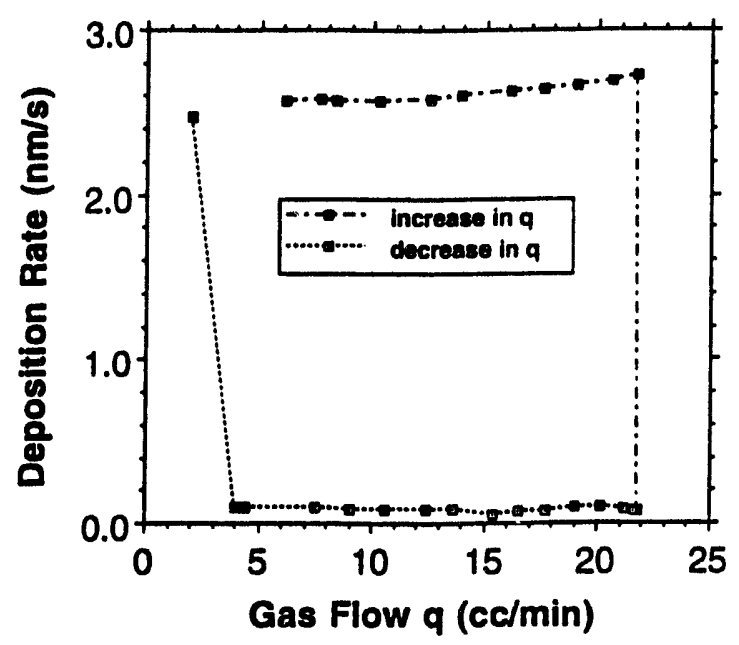

Fig.1 A hysteresis between deposition rate and gas flow is formed when yttrium is reactively sputtering with a constant flow of argon-20\%oxygen gas.

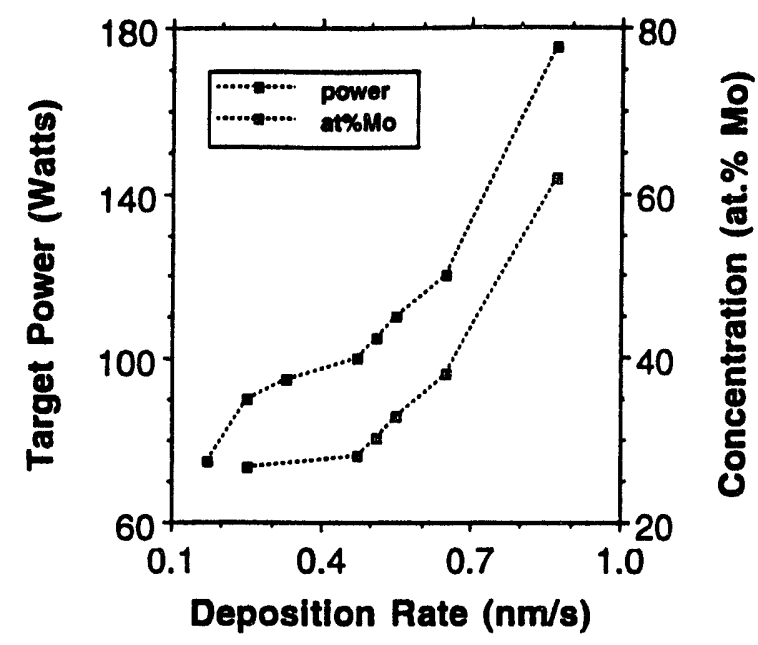

Fig. 2 The target power and concentration variation with deposition rate for molybdenum when reactively sputtered with argon-20\%oxygen gas.

The synthesis of a compositionally modulated structure of a metal-oxide system using the variation of sputter rate as the controlling deposition parameter was first shown for the Mo-O system. ${ }^{[4]}$ In this case (with reference to Fig. 2), the target power was cycled between 95 and 125 Watts producing deposition rates of 0.3 and $0.7 \mathrm{~nm} \mathrm{~s}^{-1}$, respectively. [2,3] This deposition cycle created alternating layers that were 13.6 and $14.0 \mathrm{~nm}$ thick with moybdenum concentrations of 25 and 40 at.\%, respectively. ${ }^{[2,3]}$ A high resolution electron micrograph (Fig. 3) of the Mo-O multilayer (deposited on a silicon wafer) prepared and viewed in cross-section reveals the discrete layering which results using an abrupt change (less than $1.0 \mathrm{sec}$ ) of target power. ${ }^{[4]}$ A second composition modulation example has also been demonstrated for the highly reactive yttrium-oxide system. [5] For this case, using a working gas of Ar-20\%Oxygen (at constant $0.4 \mathrm{~Pa}$ pressure and $8 \mathrm{cc} \mathrm{min}^{-1}$ flow) the target power was cycled between 140 and 390 Watts producing deposition rates of 0.6 and $1.4 \mathrm{~nm} \mathrm{~s}^{-1}$, respectively. [5] This deposition cycle created alternating layers that were each $0.35 \mu \mathrm{m}$ thick with yttrium concentrations of 40 and 60 at.\%, respectively. [1] A scanning electron micrograph (Fig. 4) of the Y-O multilayer (deposited on a $\mathrm{Ta}_{10} \mathrm{~W}$ substrate) prepared and viewed in cross-section reveals the layering which results using a gradual change of target power. ${ }^{[5]}$ The composition change is more characteristic of a sinusoidal variation for the $\mathrm{Y}-\mathrm{O}$ multilayer as opposed to a square wave for the Mo-O multilayer. The results for the $\mathrm{Cu}-\mathrm{O}$ system are introduced in this paper, wherein the variation from a "pure" metal layer to an oxide layer is shown for the first time.

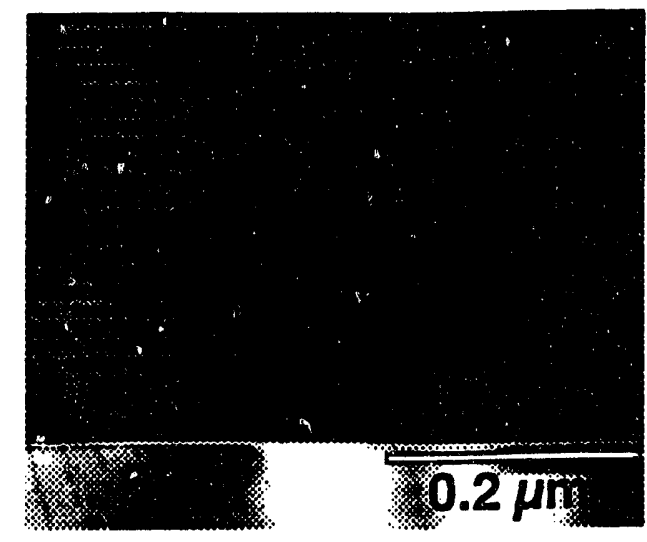

Fig. 3. A high resolution electron micrograph of a Mo-O multilayer as viewed in cross-section.

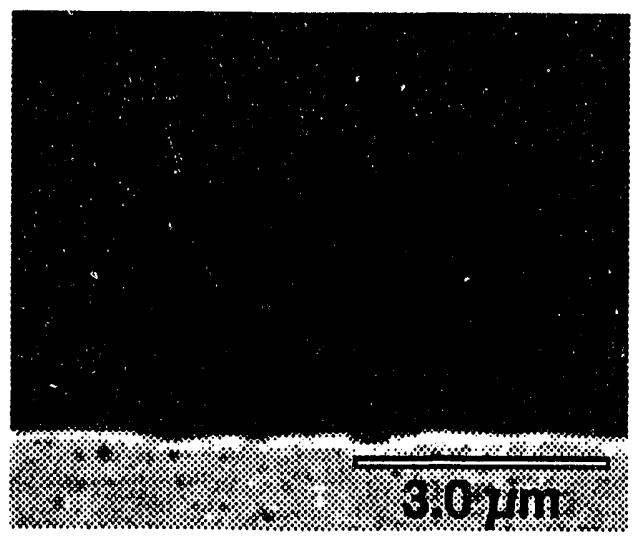

Fig. 4 A scanning electron micrograph of a Y-O multilayer as viewed in cross-section. 


\section{EXPERIMENTAL METHOD}

The metal-oxide films are prepared by reactive sputter deposition using planar magnetrons operated in the dc mode. The vacuum chamber is cryogenically pumped to a base pressure of $5.3 \mu \mathrm{Pa}$. For the synthesis of $\mathrm{Cu}-\mathrm{O}$ multilayer films, the working gas is mixed by combining flows from pure Ar and Ar-20\%Oxygen supplies at a constant pressure of $0.67 \mathrm{~Pa}$. The room temperature silicon substrates are situated $10 \mathrm{~cm}$ across from the $6.35 \mathrm{~cm}$ diameter target of 0.99995 purity. The ratio of pure $\mathrm{Ar}$ to Ar-20\% Oxygen is first determined by establishing the conditions for the deposition rate - gas flow hysteresis. The contribution of the Ar-20\% Oxygen gas source to a total flow of gas at $24.5 \mathrm{cc} \mathrm{min}-1$ is gradually reduced while the target power is maintained at 140 Watts power (Fig. 5). A sudden increase in rate is observed when the Ar-20\%Oxygen flow declines below $6.4 \mathrm{cc} \mathrm{min}^{-1}$. This mixture of gas flow should enable both metallic and oxide modes of target sputtering. A gas mixture of $15.2 \mathrm{cc} \mathrm{min}-1$ pure $\mathrm{Ar}$ and $6.8 \mathrm{cc} \mathrm{min}^{-1} \mathrm{Ar}-20 \%$ Oxygen is then used to synthesize the Cu-O multilayer. Under these constant flow conditions, the dependency is determined of deposition rate upon applied target power (Fig. 5). As expected, a sudden increase of deposition rate is found above a target power of 140 Watts. A significant change in oxide content should then result if the target power is cycled between levels which are above and below 140 Watts. A target power of 105 Watts yields a deposition rate of $0.38 \mathrm{~nm} \mathrm{~s}^{-1}$, whereas a 205 Watts yields $1.13 \mathrm{~nm} \mathrm{~s}^{-1}$. The multilayer to be examined consists of 16 layer pairs - the $32 \mathrm{~nm}$ thick Cu-rich layers are formed at 205 Watts target power for $30 \mathrm{sec}$ and the $68 \mathrm{~nm}$ thick copper-oxide layers are formed at 105 Watts for $180 \mathrm{sec}$.

The Cu-O films are structurally characterized using $x$-ray diffraction (XRD) and transmission electron microscopy (TEM). The films are examined in a powder diffractometer, operated in the $\theta / 2 \theta$ mode, usng a graphite monochromator and $\mathrm{Cu} K \alpha$ radiation. Interplanar spacings are measured via Bragg reflections which also indicate the texture and crystalline phases present in the thin film. Bright field imaging of the multilayer specimens prepared in cross-section reveal the film growth morphology and layer structure. Selected area diffraction (SAD) patterns are used to compliment phase identification from the XRD patterns. The TEM sample preparation procedure is described in typical detail elsewhere.[6] High resolution images of the crosssectioned specimens are acquired at the Scherzer defocus condition.

The Cu-O films are compositionally characterized using Auger electron spectroscopy (AES) coupled with depth profiling. The vacuum chamber is pumped to a base pressureof $0.67 \mathrm{nPa}$. A $3 \mathrm{KeV}, 10 \mu \mathrm{A}$ electron beam generates characteristic Auger electrons. The measured intensities of the CKLL $(272 \mathrm{eV}), \mathrm{O} K L L(503 \mathrm{eV})$ and $\mathrm{Cu} L M M(920 \mathrm{eV})$ Auger peaks, from data accumulated in the derivative mode, are used to compute the atomic concentrations. A $5.0 \mathrm{KV}, 2.0$ $\mu \mathrm{A}$ argon ion beam is used to sputter etch a $25 \mathrm{~mm}^{2}$ area of the multilayer at a gas pressure of $2.7 \mathrm{mPa}$.

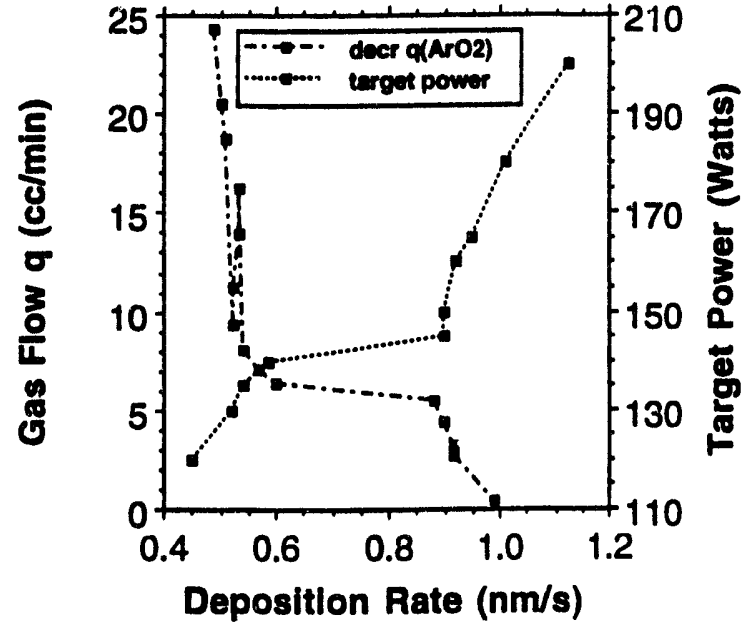

Fig. 5 The dependence of deposition rate on gas flow and target power for copper reactively sputtered with a mixture of argon and argon-20\%oxygen.

\section{EXPERIMENTAL RESULTS}

The XRD scans reveal the presence of both pure $\mathrm{Cu}$ and the $\mathrm{Cu}_{2} \mathrm{O}$ crystalline phases in the $\mathrm{Cu}-\mathrm{O}$ multilayer film. Although the film layers are polycrystalline, a preferred (111) texture is apparent for both phases. Examination of the individual films produced at 105 and $205 \mathrm{~W}$ of target power yield different intensity ratios between the $\mathrm{Cu}_{2} \mathrm{O}$ and $\mathrm{Cu}$ (111) Bragg reflections. The $105 \mathrm{Watt}$ film is almost completely $\mathrm{Cu}_{2} \mathrm{O}$ whereas the $205 \mathrm{Watt}$ film is almost completely pure $\mathrm{Cu}$.

The TEM cross-section image (Fig. 6) reveals the composition modulation of the $\mathrm{Cu}-\mathrm{O}$ multilayer. The copper-rich deposition appear as the darker thin layers. The copper-rich layers are one-half the thickness of the more oxygen-rich layers, as per the deposition parameters. The polycrystalline nature of the individual grains leads to some diffraction contrast within each layer. Layering is continuous across the densely packed columnar boundaries which are typical for sputtered thin films. The multilayer SAD pattern (Fig. 7) is indexed to the $\mathrm{Cu}$ and $\mathrm{Cu}_{2} \mathrm{O}$ crystalline structures, in agreement with the XRD results. 


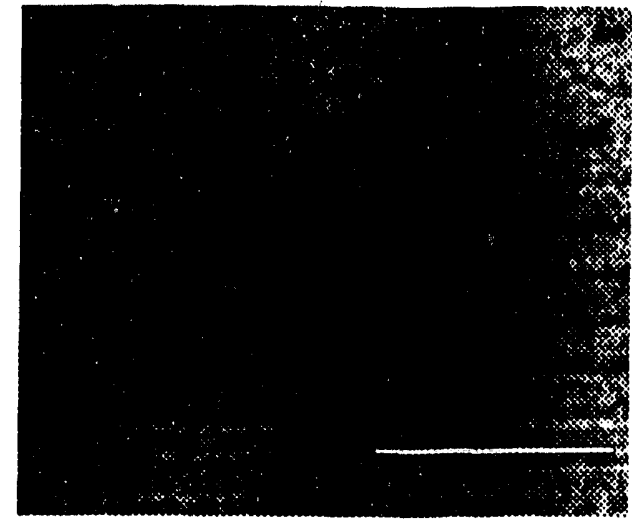

Fig. 6 A transmission electron micrograph (shown to the left) of the $\mathrm{Cu}-\mathrm{O}$ multilayer as viewed in cross-section.

Fig. 7 The selected-area diffraction (shown to the right) of the $\mathrm{Cu}-\mathrm{O}$ multilayer as imaged in plan-view.

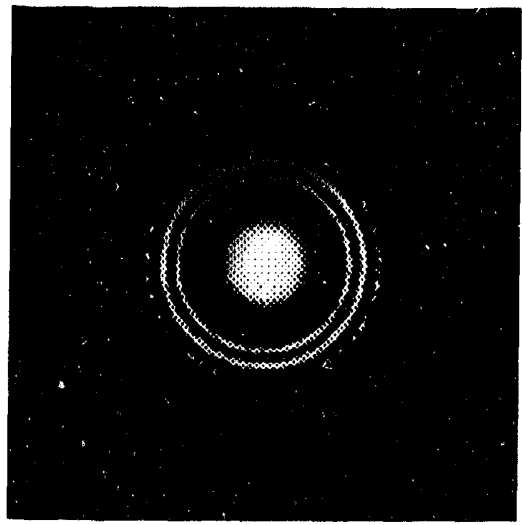

The AES profile shows a composition modulation through the film thickness consistent with a multilayer deposition (Fig. 8). Quantitatively, the 205 Watt layer is nearly pure $\mathrm{Cu}$ whereas the 105 Watt layer is 60 at.\% Cu. These concentartion values agree with the XRD phase identification of the individual 105 and 205 Watt films. Concentration levels of carbon and oxygen are at the baseline detection limit for the first layer. The ratio of oxygen concentration between the 105 and 205 Watt layers decreases from a maximum of 7:1 for the first layer pair to 5:1 by the third layer pair. This reduction is caused by nonuniform etching of the exposed surface in addition to layer intermixing during the depth profile process. The sputter time between $\mathrm{Cu}$-rich peaks remains constant during the depth profile.

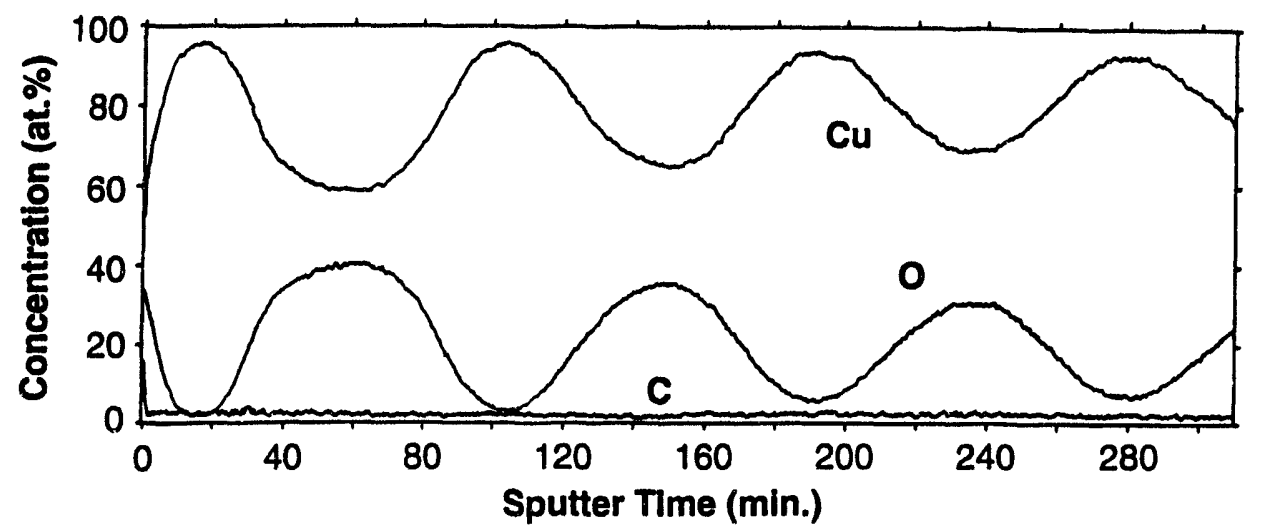

Fig. 8 The atomic concentration profile of the $\mathrm{Cu}-\mathrm{O}$ multilayer as determined from the Auger electron spectroscopy analysis.

\section{CONCLUDING REMARKS}

The optical constants measured for the Mo-O thin films range sufficiently for potential use in optical applications, as gradient-index or rugate filters. ${ }^{4]}$ Such metal-oxide multilayer filters require precise control to form the desired oxide layer thicknesses and interface composition profiles. At a nominal thickness of $1.5 \mu \mathrm{m}$, the transmission of the Mo-O films (with reference to Figs. 2 and 3 ) range from transparent ( 25 at.\% Mo) to translucent ( 40 at.\% Mo) to opaque and specular (>50 at.\% Mo). A null ellipsometer is used to measure the optical constants with the red hydrogen line at a wavelength of $656.3 \mathrm{~nm}$. The reflection ellipsometry measurement procedure and calculation method are detailed elsewhere. ${ }^{[7]}$ The refractive index $n_{c}$ and extinction coefficient $k$ are observed to vary with the deposition rate, that corresponds with changes in the oxide composition (Fig. 9). The refractive index can be varied by a factor of three whereas the extinction coefficient ranges over three-orders of magnitude. For comparison, many dielectric materials have $n_{C} \approx 2$ to 3 and $k \approx 0$ to 0.2 . 
The reactive deposition of metals is shown to be feasible for a wide range of material systems. A measure of the reactivity of the metal-oxide system is the oxide heat of formation. An order of magnitude in difference of the heat of formation $\Delta H_{0}$ is found (in Table I) from metal systems which are highly reactive (as $\mathrm{Y}-\mathrm{O}$ ) to those which are not as reactive (as $\mathrm{Cu}-\mathrm{O}$ ). [8]

Even though there is a great difference in heat of formation for metal-oxide systems, a method of reactive sputter deposition has been developed based on rate control to synthesize a continuous oxide composition range. Oxide phases can be prepared which are both equilibrium as well as metastable. [5] The rate-control method enables the deposition of multilayered oxide films with designed control over the composition profiles, which can be abrupt and/or continuous as desired.

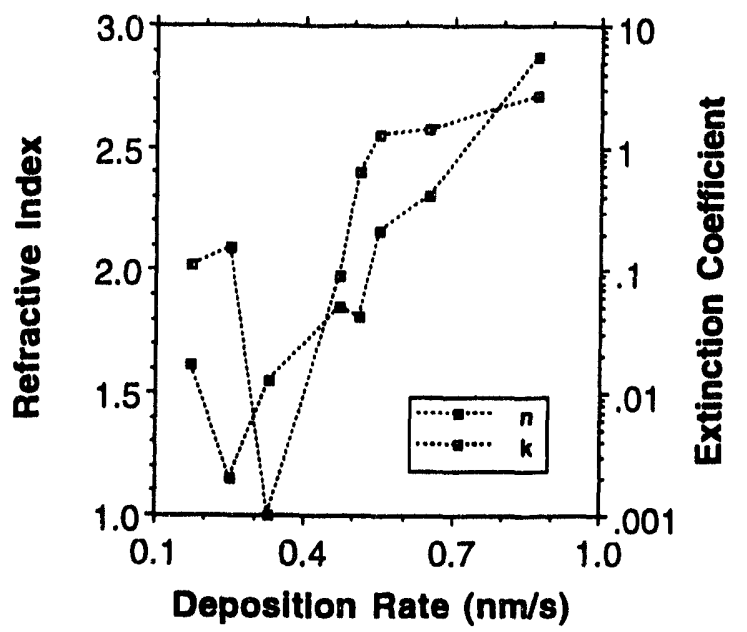

Fig. 9 The variation of refractive index and extinction coefficient with deposition rate of Mo-O.

Table 1. Metal-Oxide Heat of Formation [8]

\begin{tabular}{|c|c|c|c|c|c|}
\hline & $\mathrm{Y}_{2} \mathrm{O}_{3}$ & $\mathrm{MoO}_{3}$ & $\mathrm{MoO}_{2}$ & $\mathrm{NiO}$ & $\mathrm{Cu}_{2} \mathrm{O}$ \\
\hline$\Delta \mathrm{H}_{\mathrm{O}}\left(\mathrm{gm}-\mathrm{kcal} \mathrm{mole} \mathrm{e}^{-1}\right)$ & -419.6 & -182.7 & -132.9 & -57.64 & -40.55 \\
\hline
\end{tabular}

\section{ACKNOWLEDGMENTS}

I wish to thank J. Hayes and M. Wall for their contributions in preparation and imaging of the copper-oxide multilayer samples(s). This work was performed under the auspices of the U. S. Department of Energy by Lawrence Livermore National Laboratory under contract \#W-7405-Eng-48.

\section{REFERENCES}

1 A.F. Jankowski, L.R. Schrawyer and J.P. Hayes, "Sputter deposition of yttriumi-oxides", J. Vac. Sci. Technol. A, Vol. 11 (4), pp. 1548-1552, 1993.

2 A.F. Jankowski and L.R. Schrawyer, "Reactive sputtering of molybdenum", Thin Solid Films, Vol. 193/194, pp. 61-71, 1990.

3 A.F. Jankowski and L.R. Schrawyer, "Working gas pressure and flow effects on reactively sputtered molybdenum-oxide thin films", Surf. Coat. Technol., Vol. 54/55, pp. 349-354, 1992.

4 A.F. Jankowski, L.R. Schrawyer and P.L. Perry, "Reactive sputtering of molybdenum-oxide gradient-index filters", $J$. Vac. Sci. Technol. A, Vol. 9 (3), pp. 1184-1187, 1991.

5 A.F. Jankowski, M.P. Stratman, E.M. Sedillo, J.P. Hayes and G.F. Gallegos, "Metastability of yttrium-oxides", Surf. Coat. Technol., Vol. 61, pp. 14-19, 1993.

$6 \mathrm{~J}$. Bravman and R. Sinclair, "The preparation of cross-section specimens for transmission electron microscopy", $J$. Electr. Microsc. Technol., Vol. 1, pp. 53-61, 1984.

7 L. Ward, The Optical Constants of Bulk Materials and Films, pp. 55-57, Hilger, Bristol, 1988.

8 CRC Handbook of Chemistry \& Physics, ed. R.C. Weast, 65th edn., pp. D33-D37, CRC Press, Boca Raton, 1985. 

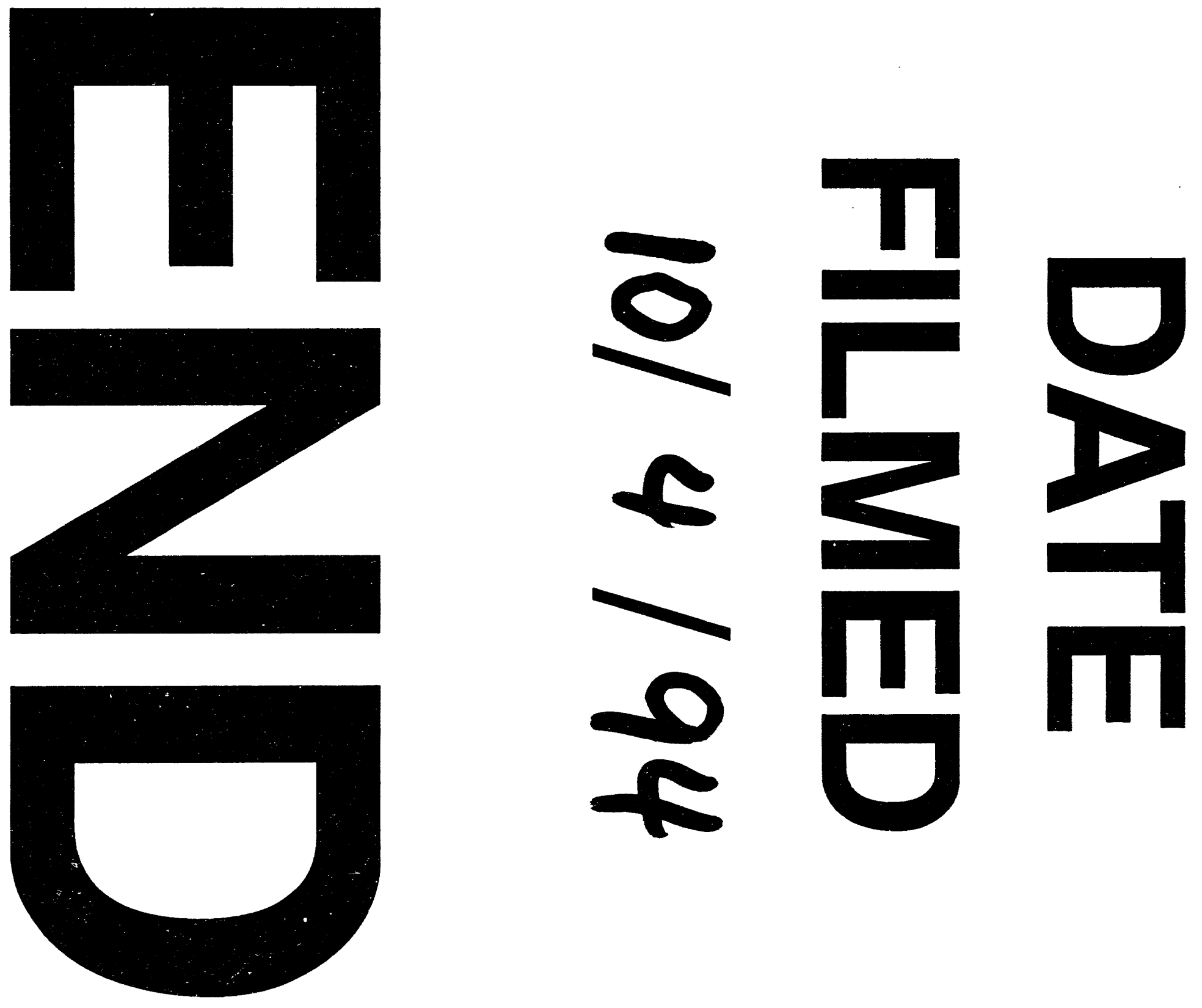
